\title{
Fucoidan reduces oxidative stress by regulating the gene expression of HO-1 and SOD-1 through the Nrf2/ERK signaling pathway in HaCaT cells
}

\author{
MIN JU RYU and HA SOOK CHUNG \\ Department of Food and Nutrition, College of Natural Sciences, \\ Duksung Women's University, Seoul 01369, Republic of Korea
}

Received May 31, 2015; Accepted June 29, 2016

DOI: $10.3892 / \mathrm{mmr} .2016 .5623$

\begin{abstract}
Fucoidan, a sulfated polysaccharide, is found in edible brown algae. In the present study, the molecular mechanisms of fucoidan against mild oxidative stress in human keratinocytes were investigated. The current study indicated that fucoidan significantly augmented the antioxidants heme oxygenase-1 (HO-1) and superoxide dismutase-1 (SOD-1) via the upregulation of nuclear factor erythroid 2-related factor 2 (Nrf2) and markedly reduced the cytoplasmic stability of kelch-like ECH-associated protein 1. The upregulation of HO-1 and SOD-1 detected in the fucoidan-treated cells may be responsible for the increased resistance to mild oxidative stress, indicating that fucoidan may augment the activities of antioxidant enzymes via stimulating Nrf2. This is the first report, to the best of our knowledge, to demonstrate that fucoidan attenuates oxidative stress by regulating the gene expression of SOD-1 and HO-1 via the Nrf2/extracellular signal-regulated kinase signaling pathway.
\end{abstract}

\section{Introduction}

Fucoidan, a sulfated polysaccharide, is found in edible brown algae, such as Undaria pinnatifida, Fucus vesiculosus

Correspondence to: Professor Ha Sook Chung, Department of Food and Nutrition, College of Natural Sciences, Duksung Women's University, 33 Samyangro 144-gil, Dobong Gu, Seoul 01369, Republic of Korea

E-mail: hasook@duksung.ac.kr

Abbreviations: HaCaT, human keratinocyte cell line; HO-1, heme oxygenase-1; SOD-1, superoxide dismutase-1; Nrf2, nuclear factor erythroid 2-related factor 2; Keap1, kelch-like ECH-associated protein 1; ERK, extracellular signal-regulated kinase; iNOS, inducible nitric oxide synthase; LPS, lipopolysaccharide; ROS, induced reactive oxygen species; ARE, antioxidant response element

Key words: fucoidan, heme oxygenase-1, superoxide dismutase-1, kelch-like ECH-associated protein 1, erythroid 2-related factor 2, extracellular signal-regulated kinase, skin protection and Ecklonia cava (1). A number of previous studies have shown that fucoidan possesses a wide variety of biological activities, including anti-coagulant (2), anti-thrombotic (3), anti-tumor (4), anti-viral (5), and anti-inflammatory activity (6). A previous study indicated that fucoidan attenuates pulmonary inflammation and reduces Th2-dominated responses, and may provide a possible strategy for treating allergic inflammation (7). Additionally, a previous study reported that fucoidan resulted in the expression of inducible nitric oxide synthase (iNOS) in macrophage cells. In particular, low concentration ranges of fucoidan $(10 \mu \mathrm{g} / \mathrm{ml})$ inhibited lipopolysaccharide (LPS)-induced nitric oxide (NO) via activator protein-1, which may be associated with anti-inflammatory effects (8). It has also been reported that fucoidan suppresses interferon (IFN)- $\gamma$-induced NO/iNOS production in glial cells via the inhibition of Janus kinase (JAK)/signal transducer and activator (STAT)/isoflavone reductase homolog 1 (IFR-1) and phospho-p38 (9).

A recent study indicated that fucoidan inhibited the LPS-induced generation of reactive oxygen species (ROS), which ultimately alleviated inflammation (10). Additionally, fucoidan-mediated apoptosis in cancer cells involved the generation of ROS, which are responsible for the loss of the mitochondrial membrane potential and the downregulation of Bcl-2 proteins (11). Therefore, fucoidan may be useful as a dietary supplement due to potential effects on preventing human disease, additionally, the polysaccharide has no associated toxicity or irritation (12). Despite evidence of a number of biological effects of fucoidan, the inflammatory cytokine combination-induced stimulation on human keratinocytes has not been investigated previously. In the present study, the molecular mechanisms of fucoidan against anti-oxidant activity through the extracellular signal-regulated kinase (ERK)/nuclear factor erythroid 2-related factor 2 (Nrf2)/heme oxygenase-1 (HO-1) signaling pathway was investigated.

\section{Materials and methods}

Materials. 3-(4,5-dimethylthiazol-2-yl)-2,5-diphenyltetrazolium bromide (MTT) and PD98059 were purchased from Sigma-Aldrich (St. Louis, MO, USA). Dulbecco's modified Eagle's medium (DMEM), fetal bovine serum (FBS), and 
streptomycin-penicillin (100 units/ml) were purchased from Gibco (Thermo Fisher Scientific, Inc., Waltham, MA, USA). Primary antibodies used in the present study included the following: Mouse anti-HO-1 (cat. no. sc-136960), mouse anti- $\beta$-actin (cat. no. sc-47778), mouse anti-superoxide dismutase-1 (SOD-1; cat. no. sc-101523), rabbit anti-Nrf2 (cat. no. sc-722), mouse anti-TATA-box binding protein (TBP; cat. no. sc-74595) and goat anti-kelch-like ECH-associated protein 1 (Keap1; cat. no. sc-15246) purchased from Santa Cruz Biotechnology, Inc. (Dallas, TX, USA); and rabbit anti-ERK (cat. no. 4695) and rabbit anti-phospho-ERK (cat. no. 4370) from Cell Signaling Technology, Inc. (Danvers, MA, USA). Secondary antibodies included goat anti-rabbit (cat. no. sc 2004) goat anti-mouse (cat. no. sc-2005) and rabbit anti-goat (cat. no. sc-2768) (Santa Cruz Biotechnology Inc.).

Cell culture. The human keratinocyte cell line (HaCaT) was purchased from the American Type Culture Collection (Manassas, VA, USA). Cells were maintained in DMEM supplemented with $10 \%$ FBS, 100 units $/ \mathrm{ml}$ penicillin and $100 \mu \mathrm{g} / \mathrm{ml}$ streptomycin in a humidified incubator under $37^{\circ} \mathrm{C}$, $5 \% \mathrm{CO}_{2}$ atmosphere. Cell counts were performed in a hemocytometer from Hausser Scientific (Horsham, PA, USA). For the experiments, fucoidan was dissolved in dimethylsulfoxide (DMSO) at concentrations not exceeding $0.01 \%$ and was then directly applied to the culture medium.

Cell viability assay. The cytotoxic effect of fucoidan on cell viability was estimated with a colorimetric assay using the MTT method, which is based on the reduction of a tetrazolium salt by a mitochondrial dehydrogenase in viable cells (13). Briefly, cells were seeded in 96-well plates and then treated with fucoidan at $1,5,10,30,50,70$ and $100 \mu \mathrm{g} / \mathrm{ml}$. After $24 \mathrm{~h}$ of incubation, MTT solution was added to each well at a final concentration of $50 \mu \mathrm{g} / \mathrm{ml}$. Following $2 \mathrm{~h}$ of incubation, the supernatants were aspirated and replaced with $150 \mu \mathrm{l}$ of DMSO to dissolve the formazan product. The absorbance at $540 \mathrm{~nm}$ was read on a spectrophotometric plate reader (Bio-Rad Laboratories, Inc., Hercules, CA, USA). Results were calculated as percentages of the unexposed control.

Preparation of nuclear extracts. Cells were harvested and lysed on ice in $1 \mathrm{ml}$ lysis buffer $(10 \mathrm{mM}$ Tris- $\mathrm{HCl}, \mathrm{pH} 7.9$; $10 \mathrm{mM} \mathrm{NaCl} ; 3 \mathrm{mM} \mathrm{MgCl}_{2}$; and 1\% NP-40) for $4 \mathrm{~min}$. Following centrifugation at $3,000 \mathrm{x}$ g for $10 \mathrm{~min}$, the pellets were resuspended in $50 \mu \mathrm{l}$ extraction buffer $(20 \mathrm{mM}$ HEPES, pH 7.9; $20 \%$ glycerol; $1.5 \mathrm{mM} \mathrm{MgCl}{ }_{2} ; 300 \mathrm{mM} \mathrm{NaCl} ; 0.2 \mathrm{mM}$ EDTA, $1 \mathrm{mM}$ dithiothreitol; and $1 \mathrm{mM}$ phenylmethylsulfonyl fluoride), incubated on ice for $30 \mathrm{~min}$, and centrifuged at $13,000 \mathrm{x} \mathrm{g}$ for $5 \mathrm{~min}$. Supernatants were harvested and stored at $-70^{\circ} \mathrm{C}$ following measurement of the protein concentration.

Immunocytochemistry. Cells were plated on coverslips, fixed with $4 \%$ paraformaldehyde for $30 \mathrm{~min}$, and permeabilized with phosphate-buffered saline (PBS) containing $0.1 \%$ Triton X-100 for $2.5 \mathrm{~min}$. They were then treated with blocking medium (PBS containing 3\% bovine serum albumin) for $1 \mathrm{~h}$ and incubated with a primary anti-Nrf2 antibody (dilution, 1:1,000) in blocking medium for $2 \mathrm{~h}$. The immunoreacted primary antibody was detected by incubating cells with a fluorescein isothiocyanate-conjugated secondary antibody (1:500 dilution; Jackson ImmunoResearch Laboratories, Inc., West Grove, PA, USA) for $1 \mathrm{~h}$. Following washing with PBS, stained cells were mounted onto microscope slides in mounting medium containing DAPI to label nuclei (Vector Laboratories, Inc., Burlingame, CA, USA). Images were collected using a Zeiss confocal microscope and Zeiss LSM 510 software (version 3.2; Zeiss AG, Oberkochen, Germany).

Reverse transcriptase-polymerase chain reaction ( $R T-P C R)$. Total RNA was isolated from cells using the TRIzol ${ }^{\circledR}$ reagent (Thermo Fisher Scientific, Inc.) according to the manufacturer's instructions and quantified by spectrophotometry. RT was conducted in a reaction composed of $40 \mu 11.25 \mathrm{X}$ reacting mix (Invitrogen; Thermo Fisher Scientific, Inc.), $1 \mu 1$ enzyme mix (Invitrogen; Thermo Fisher Scientific, Inc.), $1 \mu \mathrm{l}$ forward primer and $1 \mu \mathrm{l}$ reverse primer. cDNA synthesis was performed using the following conditions: $94^{\circ} \mathrm{C}$ for $20 \mathrm{~min}$, followed by denaturation at $94^{\circ} \mathrm{C}$ for $2 \mathrm{~min}$. PCR was subsequently performed using following conditions: Initial denaturation at $94^{\circ} \mathrm{C}$ for $5 \mathrm{~min}$, followed by 40 cycles of $94^{\circ} \mathrm{C}$ for $15 \mathrm{sec}, 52-65^{\circ} \mathrm{C}$ for $30 \mathrm{sec}$, and $68^{\circ} \mathrm{C}$ for $1 \mathrm{~min}$. The final cycle was followed by an extension step at $72^{\circ} \mathrm{C}$ for $5 \mathrm{~min}$. The primer pairs (Bioneer Corporation, Daejeon, Korea) were as follows (forward and reverse, respectively): HO-1, 5'-CCA GAAAGTGGGCATCAGCT-3' and 5'-GTCACATTTATG CTCGGCGG-3'; SOD-1, 5'-CAGCATGGGTTCCACGTC CA-3' and 5'-CACATTGGCCACACCGTCCT-3'; and $\beta$-actin, 5'-CCTCTATGCCAACACAGTGC-3' and 5'-ATACTCCTG CTTGCTGATCC-3'. Amplified products were resolved on a 1.2\% agarose gel and visualized with UV light following staining with ethidium bromide. Densitometry was performed for semi-quantification using Image J (National Institutes of Health, Bethesda, MD, USA).

Western blotting analysis. Western blot analyses were performed as previously described (14). The cells were cultured, harvested, lysed on ice for $30 \mathrm{~min}$ in lysis buffer [120 mM NaCl, $40 \mathrm{mM}$ Tris (pH 8.0), and 0.1\% NP 40] and centrifuged at $13,000 \mathrm{x}$ g for $15 \mathrm{~min}$. The protein concentration was determined using a bicinchoninic acid assay. Lysates from each sample were mixed with $5 \mathrm{X}$ sample buffer [0.375 M Tris- $\mathrm{HCl}, 5 \%$ sodium dodecyl sulfate (SDS), 5\% $\beta$-mercaptoethanol, $50 \%$ glycerol, $0.05 \%$ bromophenol blue (pH 6.8)] and heated to $95^{\circ} \mathrm{C}$ for $5 \mathrm{~min}$. Equal amounts of protein $(40 \mu \mathrm{g})$ were separated by $12 \%$ SDS-polyacrylamide gel electrophoresis and transferred onto a nitrocellulose membrane. The membranes were washed with Tris-buffered saline $(10 \mathrm{mM}$ Tris, $150 \mathrm{mM} \mathrm{NaCl})$ containing $0.05 \%$ Tween-20 (TBST) and blocked in TBST containing 5\% non-fat dried milk. The membranes were then incubated with HO-1, SOD1, Nrf2, Keap1, ERK, phospho-ERK, $\beta$-actin and TBP primary antibodies (dilution, 1:1,000) overnight at $4^{\circ} \mathrm{C}$. Following three washes in TBST, membranes were incubated with appropriate HRP-conjugated secondary antibodies (dilution, 1,200) for $1 \mathrm{~h}$ at room temperature. The membranes were further washed, and detected by an enhanced chemiluminescence western blotting detection kit (Bio-Rad Laboratories, Inc.). $\beta$-actin and TBP were used as loading 
controls for the nuclear and whole cell extracts, respectively. The values for the specific protein levels are presented as the fold-change relative to the control and densitometry was performed using Image $\mathrm{J}$.

Statistical analysis. All measurements were made in triplicate, and all values are presented as the mean \pm the standard deviation. The results were subjected to one-way analysis of variance followed by Tukey's test in order to analyze the differences between conditions. $\mathrm{P}<0.05$ was considered to indicate a statistically significant difference.

\section{Results}

Effects of fucoidan on the viability of human keratinocytes. To determine whether fucoidan can induce cytotoxicity in HaCaT cells, an MTT assay was used. As shown in Fig. 1, cells were incubated with fucoidan at various concentrations ranging from $1-100 \mu \mathrm{g} / \mathrm{ml}$ for $24 \mathrm{~h}$. It was demonstrated that, beyond the concentration of $50 \mu \mathrm{g} / \mathrm{ml}$, no significant alteration in cell viability was observed. However, fucoidan at $100 \mu \mathrm{g} / \mathrm{ml}$ exhibited significant cytotoxic effects on these cells. Thus, fucoidan at $1-50 \mu \mathrm{g} / \mathrm{ml}$ was selected for use in subsequent experiments.

Fucoidan dose-dependently induces HO-1 and SOD-1 expression. When cell viability was assessed by MTT assay, fucoidan did not exhibit any cytotoxicity at concentrations of $5,10,30$ and $50 \mu \mathrm{g} / \mathrm{ml}$. To determine whether fucoidan alters HO-1 and SOD-1 mRNA and protein expression levels, HaCaT cells were incubated in the presence of fucoidan. Fucoidan at concentrations of 5, 10 and $30 \mu \mathrm{g} / \mathrm{ml}$ dose-dependently increased HO-1 mRNA levels in HaCaT cells, while fucoidan at concentrations of $50 \mu \mathrm{g} / \mathrm{ml}$ slightly reduced expression relative to the levels induced by $30 \mu \mathrm{g} / \mathrm{ml}$ fucoidan. As presented in Fig. 2, the SOD-1 mRNA levels were markedly increased in a dose-dependent manner at $30 \mu \mathrm{g} / \mathrm{ml}$ fucoidan; however, fucoidan at $50 \mu \mathrm{g} / \mathrm{ml}$ exerted a slight reduction. Furthermore, fucoidan additionally upregulated HO-1 and SOD-1 protein expression levels in a dose-dependent manner, with a clear effect at $30 \mu \mathrm{g} / \mathrm{ml}$ of fucoidan. From these results, $30 \mu \mathrm{g} / \mathrm{ml}$ of fucoidan was selected as the optimal concentration for subsequent experiments.

Fucoidan time-dependently induces HO-1 and SOD-1 expressions. To investigate the effects of fucoidan on the expression levels of HO- 1 and SOD-1, HaCaT cells were exposed to fucoidan at times ranging from 3 to $24 \mathrm{~h}$. As shown in Fig. 3, $30 \mu \mathrm{g} / \mathrm{ml}$ fucoidan enhanced HO-1 mRNA levels in a time-dependent manner. In addition, SOD-1 levels were observed to be upregulated in a time-dependent manner following fucoidan treatment, however, fucoidan exerted a slight downregulation at $12 \mathrm{~h}$. Furthermore, increased protein expression levels of HO-1 and SOD-1 were observed at $3 \mathrm{~h}$, followed by a sustained increase in expression at $12 \mathrm{~h}$. The time course for the elevated HO-1 and SOD-1 protein expressions were closely correlated with the increased HO-1 and SOD-1 mRNA levels. These results indicate that fucoidan induces the upregulation of HO-1 and SOD-1 in HaCaT cells.
Fucoidan induces Nrf2 and Keapl expression. To explore the effects of fucoidan on the expression of $\mathrm{Nrf} 2$, HaCaT cells were treated with fucoidan at different time intervals, and western blotting was performed. As shown in Fig. 4A and B, treating $\mathrm{HaCaT}$ cells with fucoidan induced the phosphorylation of Nrf2 in a time-dependent manner, whereas Keap1 expression was reduced. Additionally, the nuclear localization of Nrf2 by fucoidan treatment was observed by immunocytochemistry. As shown in Fig. 4C, treatment with fucoidan increased the translocation of Nrf2 from the cytosol into the nucleus. These results suggest that Nrf2 protein expression and nuclear localization is induced by fucoidan treatment.

Fucoidan induces the phosphorylation of ERK. To examine the upstream signaling pathways involved in fucoidan-induced Nrf2 and HO-1 expression, cells were exposed to fucoidan for various times, and then ERK activation was analyzed by western blotting analysis using phospho-specific antibodies against ERK proteins. As shown in Fig. 5, treatment of cells with fucoidan significantly induced the phosphorylation of ERK at $12 \mathrm{~h}$, compared with the control, suggesting that fucoidan may modulate cell proliferation by the activation of the ERK signaling pathway.

Role of ERK in fucoidan-induced $\mathrm{HO}-1$ and Nrf2 expression. To investigate the role of ERK in fucoidan-induced HO-1 and Nrf2 induction, cells were pretreated with $10 \mu \mathrm{M}$ PD98059 for $1 \mathrm{~h}$ prior to incubation with fucoidan at $30 \mu \mathrm{g} / \mathrm{ml}$ for $12 \mathrm{~h}$, and then HO-1 and Nrf2 activation were analyzed by western blotting. As shown in Fig. 6, activation of HO-1 was apparent following treatment with fucoidan. The increase in HO-1 expression levels by fucoidan was markedly attenuated in PD98059 and fucoidan-treated keratocytes. These results suggest that fucoidan increased the expression levels of HO-1 and Nrf2 via ERK signaling pathways.

\section{Discussion}

In previous studies, antioxidants activated HO-1 and SOD-1 expression by targeting the antioxidant response element (ARE) sequence within the HO-1 and SOD-1 promoter region $(15,16)$. It has additionally been reported that the expression of $\mathrm{HO}-1$ is regulated by various transcription factors, such as Nrf2 (17). Nrf2, a redox-sensitive basic-leucine zipper transcription factor, serves an important role in the transactivation of genes encoding cytoprotective proteins. In unstressed cells, Nrf2 remains inactive and blocked in the cytoplasm by forming a complex with its inhibitory protein, Keap1, a negative regulator of Nrf2. However, upon exposure of cells to mild oxidative stress, Nrf2 is phosphorylated at specific serine and/or threonine residues of Nrf2, dissociates from Keap1 and translocates to the nucleus $(18,19)$. ERK is an important signaling molecule that is involved in HO-1 expression in various types of cells (20). It has been demonstrated that ERK signaling induces Nrf2 activation and regulates cellular protection against oxidative stress (21). $\mathrm{HaCaT}$ cells are a spontaneously immortalized human adult skin keratinocytes line, however, these cells are not tumorigenic. These cells retain normal keratinocyte morphology and epidermal differentiation capacity and thus offer a suitable model for in vitro studies of skin diseases $(17,22)$. 


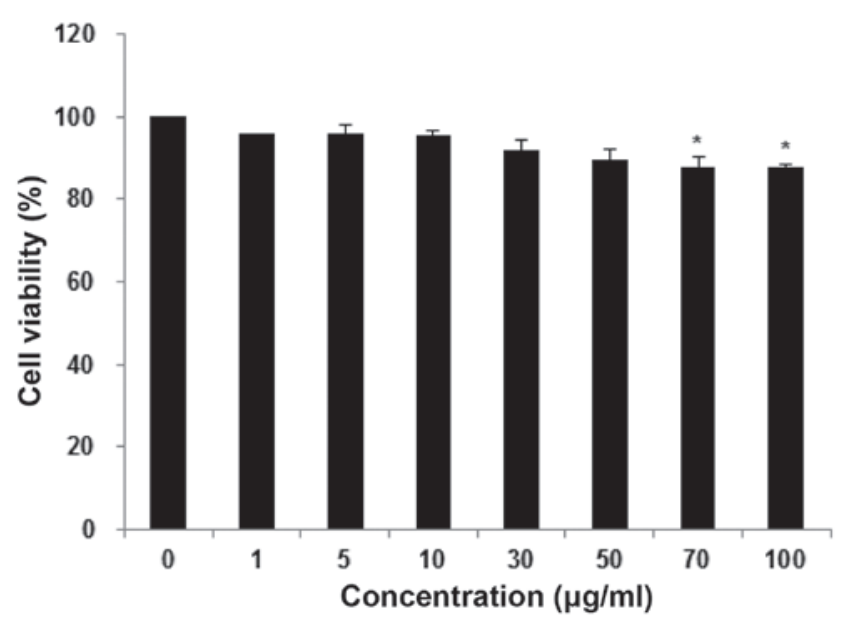

Figure 1. Effects of fucoidan on the viability of $\mathrm{HaCaT}$ cells. Cells were seeded into 96-well plates and treated with fucoidan (1-100 $\mu \mathrm{g} / \mathrm{ml})$ for $24 \mathrm{~h}$. Cell viability was measured using the 3-(4,5-dimethylthiazol-2-yl)-2,5-diphenyltetrazolium bromide assay. ${ }^{*} \mathrm{P}<0.05$ vs. the control cells.

$\mathbf{A}$
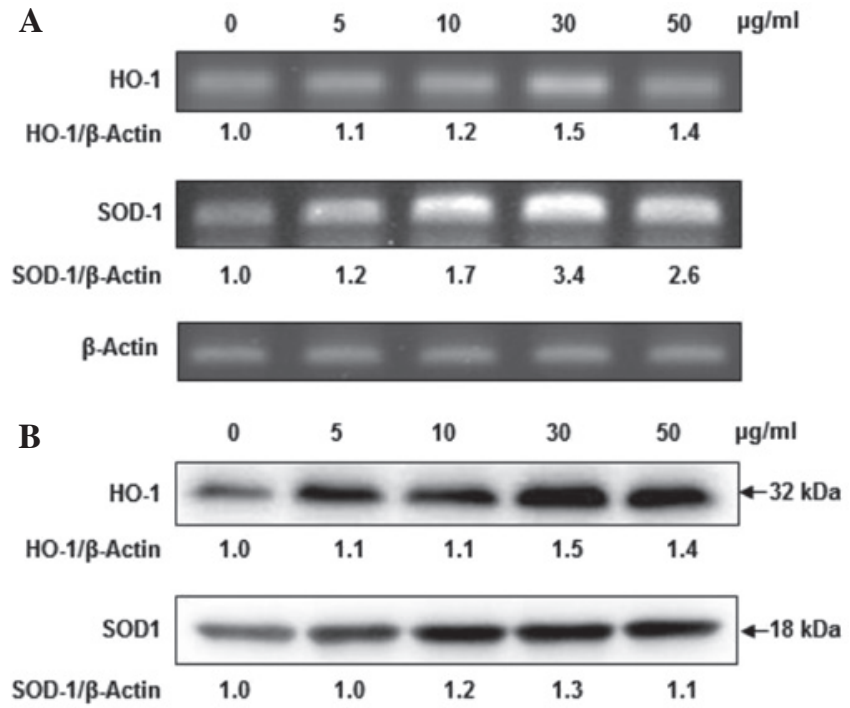

B-Actin

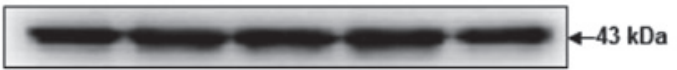

Figure 2. Effects of fucoidan on the mRNA and protein expression levels of HO-1 and SOD-1 in a dose-dependent manner. Cells were treated with concentrations of 5, 10, 30 and $50 \mu \mathrm{g} / \mathrm{ml}$ fucoidan for $24 \mathrm{~h}$. (A) mRNA levels of HO-1 and SOD-1 were analyzed with reverse transcription-polymerase chain reaction. Relative abundance of proteins was calculated for the HO- $1 / \beta$-Actin and SOD-1/ $\beta$-Actin ratios. (B) HO-1 and SOD-1 protein expression levels were analyzed by western blotting. Relative abundance of proteins was calculated for the HO- $1 / \beta$-Actin and SOD-1/ $\beta$-Actin ratios. HO- 1 , heme oxygenase-1; SOD-1, superoxide dismutase 1.

The possible molecular mechanism of fucoidan against mild oxidative stress was investigated, and the Nrf-2/HO-1 signaling pathway was focused on. The current study has indicated that fucoidan significantly augmented the antioxidants HO-1 and SOD-1 via the upregulation of Nrf2 and markedly reduced the cytoplasmic stability of Keap1. Additionally, Nrf2 was only present in the cytoplasm of cells in the control group, however, was observed to accumulate in the nucleus following fucoidan treatment, indicating that fucoidan facilitated the Nrf2 translocation from the cytoplasm to the nucleus.
A
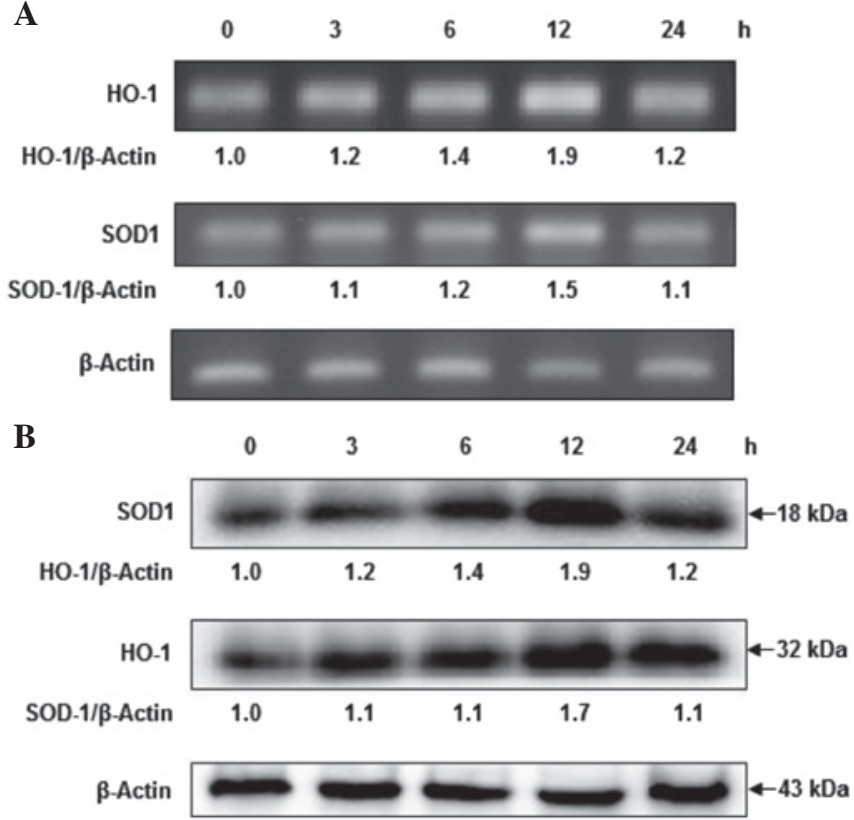

Figure 3. Effects of fucoidan on the mRNA and protein expression levels of HO-1 and SOD-1 in a time-dependent manner. (A) Cells were treated with $30 \mu \mathrm{g} / \mathrm{ml}$ fucoidan for $0,3,6,12$ and $24 \mathrm{~h}$, and the mRNA levels of HO-1 and SOD-1 analyzed by reverse trancription-polymerase chain reaction. Relative abundance of proteins was calculated for the HO- $1 / \beta$-Actin and SOD-1/ $\beta$-Actin ratios. (B) Cells were treated with $30 \mu \mathrm{g} / \mathrm{ml}$ fucoidan for 0 , 3, 6, 12 and $24 \mathrm{~h}$, and HO-1 and SOD-1 protein expression were analyzed by western blotting. Relative abundance of proteins was calculated for the HO- $1 / \beta$-Actin and SOD-1/ $\beta$-Actin ratios. HO-1, heme oxygenase-1; SOD-1, superoxide dismutase 1 .

Nrf2 is a ubiquitously expressed transcription factor that is present in a wide range of tissues and cells, including keratinocytes (23). Normally, Nrf2 is sequestered in the cytoplasm by Keap1. However under mild oxidative stress, disruption of the Keap1-Nrf2 complex results in the nuclear translocation of $\mathrm{Nrf} 2$ and its subsequent binding to promoter regions of antioxidant enzymes, including HO-1 and SOD-1 $(24,25)$.

Accumulating evidence supports a role for the ERK pathway in HO-1 expression. In a previous study, 7,8-dihydroxyflavone regulated $\mathrm{HO}-1$ expression through the activation of Nrf2 and Keap1 degradation in an ERK-dependent pathway in HaCaT cells (15). In addition, specific inhibitors of ERK reduced the accumulation of HO-1 and phospho-Nrf2 through the inhibition of ERK phosphorylation, indicating that Nrf2 is a direct downstream target of ERK (26). It has also been reported that fucoidan suppresses IFN- $\gamma$-induced $\mathrm{NO} /$ iNOS production in glial cells via the inhibition of JAK/STAT/IFR-1 and phospho-p38 (9). Therefore, fucoidan may be hold potential as a dietary supplement for the prevention of human diseases, as its polysaccharide has no toxic or irritating side effects (12).

In the present study, the molecular mechanisms of fucoidan anti-oxidant activity via the ERK/Nrf2/HO-1 signaling pathway were investigated. The results indicated that Nrf2 protein expression levels and the accumulation of Nrf2 in the nucleus was increased, and that Keap1 protein expression was reduced in the fucoidan-treated cells. The upregulation of HO-1 and SOD-1 detected in the fucoidan-treated cells may be responsible for the increased 
A

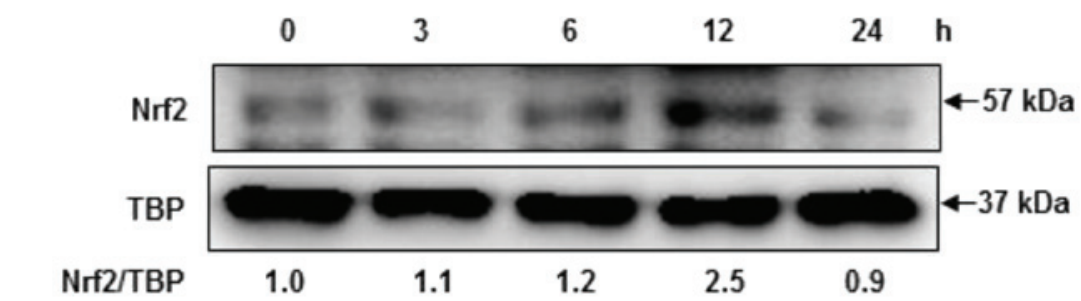

B

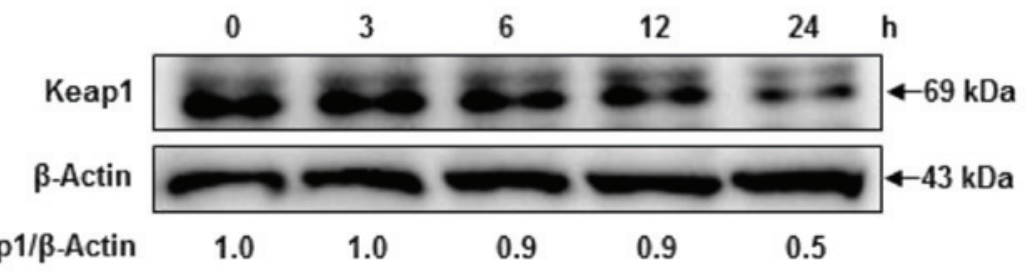

C Nrf2-FITC
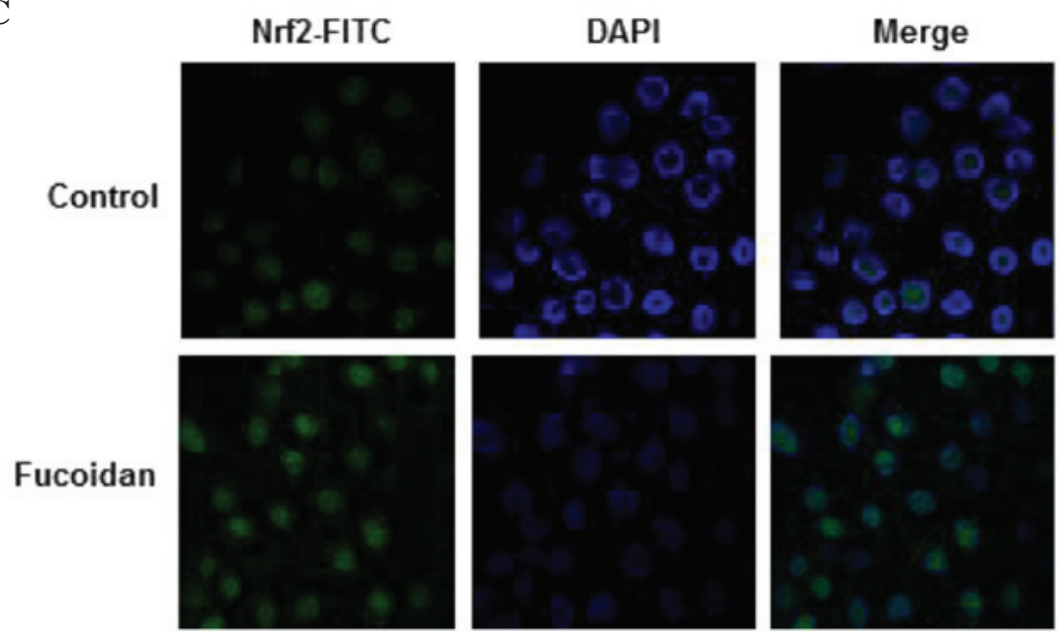

Figure 4. Effects of fucoidan on the expression levels of Nrf2 and Keap1. Cells were treated with $30 \mu \mathrm{g} / \mathrm{ml}$ fucoidan for 0,3,6, 12 and $24 \mathrm{~h}$. (A) Nrf2 levels were analyzed by subjecting nuclear extracts to western blotting with anti-Nrf2 antibodies. Relative abundance of proteins was calculated as the Nrf2/TBP ratio. (B) Keap1 expression was analyzed by subjecting cell lysates to western blotting with an anti-Keap1 antibody. Relative abundance of proteins was calculated as the Keap1/ $\beta$-actin ratio. (C) Cells were treated with $30 \mu \mathrm{g} / \mathrm{ml}$ fucoidan for $12 \mathrm{~h}$ and the nuclear localization of Nrf2 was detected by immunocytochemistry. Nrf2 was labeled with an anti-Nrf2 antibodies (green) and DAPI staining indicates the location of nuclei (blue). Merged images illustrate that nuclear translocation of Nrf2 is enhanced in fucoidan-treated cells in comparison with control cells. Nrf2, nuclear factor erythroid 2-related factor 2; TBP, TATA-box binding protein; Keap1, kelch-like ECH-associated protein 1; DAPI, 4',6-diamidino-2-phenylindole; FITC, fluorescein isothiocyanate.

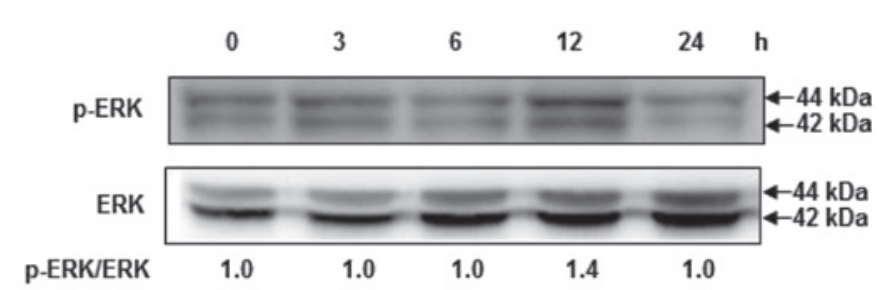

Figure 5. Effects of fucoidan treatment on the expression of ERK. Cells were treated with $30 \mu \mathrm{g} / \mathrm{ml}$ fucoidan for 0, 3, 6, 12 and $24 \mathrm{~h}$, and ERK protein expression levels were analyzed by western blotting. Relative abundance of proteins was calculated as the p-ERK/ERK ratios. ERK, extracellular signal-regulated kinase; p-ERK, phosphorylated ERK.

resistance to mild oxidative stress, indicating that fucoidan may augment the activities of antioxidant enzymes via stimulating Nrf2. These results clearly indicate that fucoidan is an effective component in food supplements used for skin protection. To the best of our knowledge, this is the first report, to demonstrate that fucoidan attenuates oxidative stress by regulating the gene expression of SOD-1 and HO-1 via the Nrf2/ERK signaling pathway.

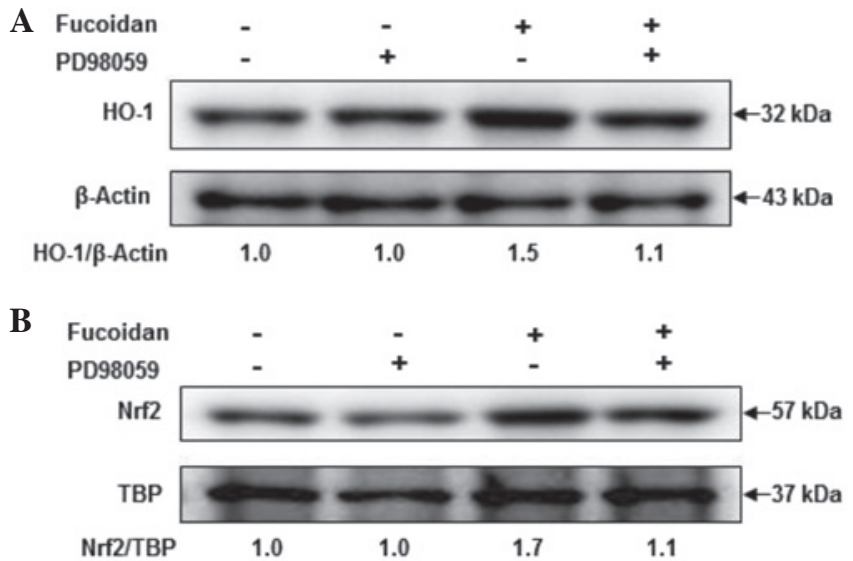

Figure 6. Role of extracellular signal-regulated kinase in fucoidan-induced HO-1 and Nrf2 expression. Cells were pretreated with $10 \mu \mathrm{M}$ PD98059 for $1 \mathrm{~h}$ prior to incubation with $30 \mu \mathrm{g} / \mathrm{ml}$ fucoidan for $12 \mathrm{~h}$. (A) Cells were harvested and HO-1 expression were determined by western blotting. Relative abundance of proteins was calculated as the HO- $1 / \beta$-actin ratio. (B) Cells were harvested and Nrf2 expression was determined by western blotting. Relative abundance of proteins was calculated as the Nrf2/TBP ratio. HO-1, heme oxygenase-1; Nrf2, nuclear factor erythroid 2-related factor 2; TBP, TATA-box binding protein. 


\section{References}

1. Patankar MS, Oehninger S, Barnett T, Williams RL and Clark GF: A revised structure for fucoidan may explain some of its biological activities. J Biol Chem 268: 21770-21776, 1993.

2. Durig J, Bruhn T, Zurborn KH, Gutensohn K, Bruhn HD and Béress L: Anticoagulant fucoidan fractions from Fucus vesiculosus induce platelet activation in vitro. Thromb Res 85: 479-491, 1997.

3. Soeda S, Kozako T, Iwata K and Shimeno H: Oversulfated fucoidan inhibits the basic fibroblast growth factor-induced tube formation by human umbilical vein endothelial cells: Its possible mechanism of action. Biochim Biophys Acta 1497: 127-134, 2000.

4. Teruya $\mathrm{T}$, Konishi $\mathrm{T}$, Uechi $\mathrm{S}$, Tamaki $\mathrm{H}$ and Tako $\mathrm{M}$ : Anti-proliferative activity of oversulfated fucoidan from commercially cultured Cladosiphon okamuranus TOKIDA in U937 cells. Int J Biol Macromol 41: 221-226, 2007.

5. Thompson KD and Dragar C: Antiviral activity of Undaria pinnatifida against herpes simplex virus. Phytotherapy Res 18: 551-555, 2004.

6. Cumashi A, Ushakova NA, Preobrazhenskaya ME, D'Incecco A, Piccoli A, Totani L, Tinari N, Morozevich GE, Berman AE, Bilan MI, et al: A comparative study of the anti-inflammatory, anticoagulant, antiangiogenic and antiadhesive activities of nine different fucoidans from brown seaweeds. Glycobiol 17: 541-552, 2007.

7. Maruyama H, Tamauchib H, Hashimotoc M and Nakano T: Suppression of Th2 immune responses by Mekabu fucoidan from Undaria pinnatifida Sporophylls. Int Arch Allergy Immunol 137: 289-294, 2005.

8. Yang JW, Yoon SY, Oh SJ, Kim SK and Kang KW: Biofunctional effects of fucoidan on the expression of inducible nitric oxide synthase. Biochem Biophys Res 346: 345-350, 2006.

9. Do H, Kang NS, Pyo SK, Billiar TR and Sohn EH: Differential regulation by fucoidan of IFN- $\gamma$-induced NO production in glial cells and macrophages. J Cell Biochem 111: 1337-1345, 2010 .

10. Lee SH, Ko CL, Jee Y, Jeong Y, Kim M, Kim JS and Jeon YJ: Anti-inflammatory effect of fucoidan extracted from Ecklonia cava in zebrafish model. Carbohydr Polym 92: 84-89, 2013.

11. Zhang H, Teruya K, Eto H and Shirahata S: Fucoidan extract induces apoptosis in MCF-7 cells via a mechanism involving the ROS-dependent JNK activation and mitochondria-mediated pathways. PLoS One 6: e27441, 2011.

12. Matsumoto S, Nagaoka M, Hara T, Kimura-Takagi I, Mistuyama K and Ueyama S: Fucoidan derived from Cladosiphon okamuranus Tokida ameliorates murine chronic colitis through the down-regulation of Interleukin-6 production on colonic epithelial cells. Clin Exp Immunol 136: 432-439, 2004.

13. Carmichael J, DeGraff WG, Gazdar AF, Minna JD and Mitchell JB: Evaluation of a tetrazolium-based semiautomated colorimetric assay: Assessment of chemosensitivity testing. Cancer Res 47: 936-942, 1987.
14. Ryu MJ, Kim AD, Kang KA, Chung HS, Suh IS, Chang WY and Hyun JW: The green algae Ulva fasciata Delile extract induces apoptotic cell death in human colon cancer cells. In Vitro Cell Dev Biol Anim 49: 74-81, 2013.

15. Ryu MJ, Kang KA, Piao MJ, Kim KC, Zheng J, Yao CW, Cha JW, Chung HS, Kim SC, Jung E, et al: 7,8-Dihydroxy flavone protects human keratinocytes against oxidative stress-induced cell damage via the ERK and PI3K/Akt-mediated Nrf2/HO-1 signaling pathways. Int J Mol Med 33: 964-970, 2014.

16. Kim KC, Lee IK, Kang KA, Piao MJ, Ryu MJ, Kim JM, Lee NH and Hyun JW: Triphlorethol-A from Ecklonia cava up-regulates the oxidant sensitive 8-oxoguanine DNA glycosylase 1. Mar Drugs 12: 5357-5371, 2014.

17. Kundu J, Kim DH, Kundu JK and Chun KS: Thymoquinone induces heme oxygenase- 1 expression in HaCaT cells via Nrf2/ARE activation: Akt and AMPK $\alpha$ as upstream targets. Food Chem Toxicol 65: 18-26, 2014.

18. Dinkova-Kostova AT, Holtzclaw WD, Cole RN, Itoh K, Wakabayashi N, Katoh Y, Yamamoto M and Talalay P: Direct evidence that sulfhydryl groups of Keapl are the sensors regulating induction of phase 2 enzymes that protect against carcinogens and oxidants. Proc Natl Acad Sci USA 99: 11908-11913, 2002.

19. Wakabayashi N, Dinkova-Kostova AT, Holtzclaw WD, Kang MI, Kobayashi A, Yamamoto M, Kensler TW and Talalay P: Protection against electrophile and oxidant stress by induction of the phase 2 response: Fate of cysteines of the Keap1 sensor modified by inducers. Proc Natl Acad Sci USA 101: 2040-2045, 2004.

20. Li X and Darzynkiewicz Z: Cleavage of poly(ADP-ribose) polymerase measured in situ in individual cells: Relationship to DNA fragmentation and cell cycle position during apoptosis. Exp Cell Res 255: 125-132, 2000.

21. Yu R, Chen C, Mo YY, Hebbar V, Owuor ED, Tan TH and Kong AN: Activation of mitogen-activated protein kinase pathways induces antioxidant reponse element-mediated gene expression via a Nrf2-dependent mechanism. J Biol Chem 275: 39907-39913, 2000.

22. Boukamp P, Petrussevska RT, Breitkreutz D, Hornung J, Markham A and Fusenig NE: Normal keratinization in a spontaneously immortalized aneuploidy human keratinocyte cell line. J Cell Biol 106: 761-771, 1998.

23. Baraun S, Hanselmann C, Gassmann MG, auf dem Keller U, Born-Berclaz C, Chan K, Kan YW and Werner S: Nrf2 transcription factor, a novel target of keratinocyte growth factor action which regulates gene expression and inflammation in the healing skin wound. Mol Cell Biol 22: 5492-5505, 2002.

24. Jain AK, Mahajan S and Jaiswal AK: Phosphorylation and dephosphorylation of tyrosine 141 regulate stability and degradation of INrf2: A novel mechanism in Nrf2 activation. J Biol Chem 283: 17712-17720, 2008.

25. Lee OH, Jain AK, Papusha V and Jaiswal AK: An auto-regulatory loop between stress sensors INrf2 and Nrf2 controls their cellular abundance. J Biol Chem 282: 36412-36420, 2007.

26. Cullinan SB and Diehl JA: PERK-dependent activation of Nrf2 contributes to reox homeostasis and cell survival following endoplasmic reticulum stress. J Biol Chem 279: 20108-20117, 2004. 